\title{
O COTIDIANO DE PESSOAS COM TRANSTORNO ESPECTRO AUTISTA DE ALTA FUNCIONALIDADE: uma análise da Série Atypical
}

DOI: 10.22289/2446-922X.V6N2A22

Nara Moreira Baldoino ${ }^{1}$

Delza Ferreira Mendes

\section{RESUMO}

O autismo é classificado como um transtorno global do desenvolvimento, caracterizado pelo crescimento acentuadamente atípico na interação social e na comunicação e pela presença de um repertório restrito de atividades e interesses pessoais (APA, 2013). Com base nisso foi realizado este ensaio-análise da série americana Atypical. O personagem principal da série, um jovem de 18 anos diagnosticado com Transtorno Espectro autista (TEA) passa por momentos de angústia, quando busca sua independência, possuindo uma mãe superprotetora, uma irmã mais velha que procura acolhe-lo, um pai com dificuldades em comunica-se com ele e amigos que servem como motivação para seu desenvolvimento diário. Postula-se a ideia de que quando acontece uma doença ou deficiência num dos membros da família, ocorre um encadeamento de estádios emocionais e atitudinais aproximadamente constante e universal, sendo estes: choque, negação, depressão, adaptação e reorganização. Pode-se afirmar que a discussão do tema abordado é de total relevância para que haja maior inclusão de pacientes com TEA, pretendendo-se contribuir para o aumento de conhecimento da sociedade sobre os desafios enfrentados pelos pacientes autistas, seus familiares e amigos.

Palavras-chave: TEA; Transtorno; Autismo; Funcionalidade; Emocional; Social.

\section{THE EVERYDAY OF PEOPLE WITH HIGH FUNCTIONAL AUTISTIC SPECTRUM DISORDER: an analysis of the Atypical Series}

\section{ABSTRACT}

Autism is classified as a global developmental disorder, characterized by growth sharply atypical in social interaction and in communication and the presence of a restricted repertoire of activities and personal interests (APA, 2013). Based on this was realized this analysis essay of the American series Atypical, where the main character Samuel, a young of 18 years old diagnosed with ASD goes through moments of anguish, when seeks his independence, having an overprotective mother, an older sister who seeks to welcome, a father having difficulty communicating with him and friends who serve as motivation for your daily development.

The idea is postulated that when an illness or disability occurs in one of the family members,

\footnotetext{
${ }^{1}$ Endereço eletrônico de contato: naramoreira04@gmail.com

Recebido em 30/09/2020. Aprovado pelo conselho editorial para publicação em 06/11/2020.
}

Rev. Psicol Saúde e Debate. Dez., 2020:6(2): 338-34. 
a chain of emotional stages occurs and attitudinal approximately constant and universal, these being: shock, denial, depression, adaptation and reorganization (Klüber-Ross, 1996). It can be said that the discussion of the topic addressed is of total relevance so that there is greater inclusion of patients with ASD, intending to contribute to the increase of society's knowledge about the challenges faced by autistic patients, their families and friends.

Keywords: ASD; Disorder; Autism; Functionality; Emotional; Social.

\section{EL DÍA DÍA DE LAS PERSONAS CON TRASTORNO DEL ESPECTRO AUTISTA ALTO FUNCIONAL: un análisis de la Serie Atípica}

\section{RESUMEN}

El autismo se clasifica como un trastorno del desarrollo global, caracterizado por un crecimiento marcadamente atípico en la interacción social y la comunicación y la presencia de un repertorio restringido de actividades e intereses personales (APA, 2013). En base a esto, se llevó a cabo este ensayo-análisis de la serie estadounidense Atypical. El personaje principal de la serie, un joven de 18 años diagnosticado con Trastorno del Espectro Autista (TEA), atraviesa momentos de angustia cuando busca su independencia, teniendo una madre sobreprotectora, una hermana mayor que busca acogerlo, un padre con dificultades en se comunica con él y sus amigos que le sirven de motivación para su desarrollo diario. Se postula la idea de que cuando ocurre una enfermedad o discapacidad en uno de los miembros de la familia, existe una cadena aproximadamente constante y universal de etapas emocionales y actitudinales, las cuales son: shock, negación, depresión, adaptación y reorganización. Se puede decir que la discusión del tema abordado es de suma relevancia para que exista una mayor inclusión de los pacientes con TEA, con el objetivo de contribuir a incrementar el conocimiento de la sociedad sobre los desafíos que enfrentan los pacientes autistas, sus familiares y amigos.

Palabras clave: DEA; Transtorno; Autismo; Funcionalidad; Emocional; Social.

\section{INTRODUÇÃO}

As manifestações clínicas são bem características nos portadores de Transtorno do Espectro Autista (TEA), variando na gravidade das apresentações e o diagnóstico deve ser clínico, baseado nos critérios do Manual Diagnóstico e Estatístico de Transtornos Mentais (DSM V). A medida empregada para avaliar o perfil de desenvolvimento e da cognição de crianças e jovens depende da idade e da funcionalidade da pessoa com TEA (Associação Americana de Psiquiatria [Apa], 2013).

O TEA é definido pela interação entre fatores ambientais e diversos genes. Estudos com gêmeos monozigóticos têm apontado uma taxa de concordância faltosa, o que reforça a contribuição de fatores ambientais na etiologia do TEA. Estudos moleculares destacam a epigenética no desenvolvimento cerebral como um processo potencialmente causador desse transtorno (Maia et al., 2018).

Rev. Psicol Saúde e Debate. Dez., 2020:6(2): 338-345. 
O papel dos fatores ambientais na determinação do TEA é consistente com a heterogeneidade clínica, característica marcante desse transtorno, e sugere uma explicação para o aumento dos casos nas últimas décadas. O TEA passou de 4 a 5 casos por 10 mil nascimentos na década de 1960 para cerca de 40 a 60 casos a cada 10 mil no ano de 2009 . Em um estudo desenvolvido com crianças norte-americanas, no ano de 2014, observou-se uma prevalência de 1 para 59 indivíduos. (Maia et al., 2018, s.p.).

O autismo é classificado como um transtorno global do desenvolvimento, caracterizado pelo crescimento acentuadamente atípico na interação social e na comunicação e pela presença de um repertório restrito de atividades e interesses pessoais. Os comprometimentos nessas áreas estão presentes antes dos três anos de idade, quando os pais, geralmente percebem e preocupam com as limitações vistas nos filhos, que se tornam cada vez mais aparentes ao longo do desenvolvimento da criança. Desse modo, é observado desde cedo nos pacientes com TEA uma dificuldade qualitativa de relacionarem e comunicarem de maneira simples com as pessoas (Apa, 2013).

As dificuldades na interação social nos portadores do TEA podem manifestar-se como isolamento ou comportamento social impróprio, pobre contato visual, dificuldade em participar de atividades em grupo, indiferença afetiva ou demonstrações inapropriadas de afeto, falta de empatia social ou emocional. À medida que esses indivíduos entram na idade adulta, há, em geral, uma melhora do isolamento social, mas a pobre habilidade social e a dificuldade em estabelecer amizades persistem.

Muitos adultos com transtorno do espectro autista sem deficiência intelectual ou linguística aprendem a suprimir comportamentos repetitivos em público. Interesses especiais podem constituir fonte de prazer e motivação, propiciando vias de educação e emprego mais tarde na vida. Os critérios diagnósticos podem ser satisfeitos quando padrões limitados e repetitivos de comportamento, interesses ou atividades estiverem claramente presentes na infância ou em algum momento do passado mesmo que os sintomas não estejam mais presentes. (Apa, 2013, p. 54).

A APA atribui o TEA a três níveis diferenciados. No nível 1 os sintomas são considerados mais suaves de acordo com os outros níveis, os pacientes apresentam pequenos sintomas que não prejudicam de maneira extrema o convívio social, como trabalhar, estudar e se relacionar afetivamente. No nível 2 os pacientes necessitam de maior apoio e atenção da família e de profissionais capacitados, efetuando sessões de terapia e acompanhamento com fonoaudiólogos, para que ocorra um aumento nas interações sociais, melhorando as alterações de comportamentos e na linguagem, quanto mais cedo o início do tratamento, maiores são os resultados. O terceiro nível de autismo é o mais severo, onde são necessárias terapias de maneira intensiva, para que ocorra maior estimulo no desenvolvimento do paciente, contudo, é de extrema importância a ajuda

Rev. Psicol Saúde e Debate. Dez., 2020:6(2): 338-345. 
da família e de amigos, não podendo ficar sozinho devido suas limitações físicas e cognitivas (Apa, 2013).

A adequação do comportamento dos pais a uma criança com limitações pode ser um processo extenso e complicado, sendo de extrema importância poder contar com a colaboração dos que estão mais próximos: familiares, amigos, outros pais com dificuldades semelhantes e profissionais especializados na demanda. Para que os pais possam se adaptarem a realidade dos filhos com TEA são utilizadas estratégias de percepção positiva que são esforços cognitivos e comportamentais que ajudam o paciente a lidar com situações de danos, ameaças ou desafios quando não possuem uma resposta automática ou rotina sobre determinado acontecimento. É necessário investigar quais são as necessidades dos familiares e as possíveis implicações no bemestar psicológico e pessoal de pais de crianças e jovens com autismo (Marques \& Dixe, 2011).

Segundo Delion (2015):

As patologias artísticas são complexas e requerem uma atenção especifica para cada criança. Na organização que preside os tratamentos, a Psicoterapia Institucional tem uma grande importância devido à sua larga experiência com as psicopatologias graves como o autismo e a psicose. No projeto terapêutico da criança, a implicação e o papel dos pais são determinantes para sua orientação e indispensáveis para dar lhe sentido. (p. 1).

O presente ensaio-análise tem por objetivo buscar mais informações sobre o TEA, com o intuito de motivar os leitores em relação à inclusão, além de demonstrar o quanto a família influencia grandemente na vida de uma pessoa que possui o transtorno.

Para um melhor entendimento sobre a patologia foram realizados estudos teóricos aprofundados juntamente com uma análise sobre a série Atypical, onde o personagem principal possui TEA de alta funcionalidade e se desenvolve gradativamente em suas relações interpessoais e intrapessoais, com a ajuda da família, amigos e acompanhamento psicológico.

\section{SÉRIE ATYPICAL: o cotidiano de um autista}

Na série americana Atypical, o personagem principal Samuel (Keir Gilchrist), um jovem de 18 anos diagnosticado com TEA passa por momentos de angústia, quando busca sua independência, possuindo uma mãe superprotetora (Elsa - Jennifer Jason Leigh), na qual tenta executar todas as tarefas necessárias para que seu filho mais velho não precise se preocupar, porém, na verdade ela busca impedir com que Sam sofra alguma alteração de comportamento em público, pois possui dificuldades em relação ao excesso de luzes, pessoas e barulhos.

Casey é irmã mais nova de Sam, que procura protege-lo dos adolescentes da escola onde ela e seu irmão estudam durante a parte da manhã, pois Sam é tratado como anormal pelos outros 
estudantes, exceto por Paige (Jenna Boyd), que vê nele alguém especial, atípico e busca sua companhia por diversas vezes, até conseguir aos poucos se tornar a melhor amiga de Sam e posteriormente sua namorada.

Juntos Paige ajudou Sam em diversas situações, demonstrando sempre empatia, entendimento sobre seu transtorno e vontade em ajuda-lo no que fosse possível em cada momento que passavam juntos, fazendo com que Sam ficasse menos abalado psicologicamente e seu comportamento pudesse ser moderado de acordo com cada novidade que ele tivesse que enfrentar no dia a dia, vencendo algumas de suas angústias com força e determinação, sem perder o ânimo diário em cada conquista que era sempre comemorada.

Doug (Michael Rapapor), pai de Samuel, o abandonou quando era apenas uma criança, pois não estava conseguindo lidar com a realidade de ter um filho autista de alta funcionalidade. Doug ficou 8 meses longe de sua família - Elsa, Sam e Casey - se arrependeu profundamente de sua atitude, tentando se reaproximar de Sam e buscando entender mais sobre o TEA, para facilitar o convívio e a comunicação entre eles, porém nunca havia contado para seus amigos e colegas de trabalho que tinha um filho autista.

Evan (Graham Rogers), namorado de Casey teve o papel fundamental em incentivar sua namora e os pais dela a buscarem superar o passado, como a traição de Elsa, o abandono de Doug devido a insegurança e o despreparo psíquico para agir com a determinada situação exigida naquele momento.

Sam trabalhava no período da tarde em uma loja de vendas de aparelhos eletrônicos, onde era extremamente dedicado e estudava tudo sobre cada produto que vendia para melhor atender as necessidades dos clientes, sendo um funcionário de destaque e querido por seu chefe. No local de trabalho foi onde Sam conheceu seu melhor amigo e conselheiro Zahid (Nik Dodani), que o ajudou em suas questões amorosas decorrentes de sua idade, tentou diminuir os níveis de ansiedade de Sam em relação a ter uma namorada, e o fez perceber que alguns sentimentos podem ser semelhantes, porém não iguais, como o amor por alguém que sente admiração e o amor carnal.

A psicóloga Julia (Amy Okuda) fez uma participação grandiosa na série, onde foi possível demonstrar a transferência positiva entre a psicóloga e o jovem paciente, fazendo com que Sam desenvolvesse mais as suas habilidades e maneiras de interpretação dos comportamentos de outras pessoas em relação a ele e dele com o externo. Em alguns momentos da série Sam repetia mecanicamente em sua mente uma palavra que ouvia e acabava falando ela fora do contexto, isso é bastante comum em portadores de TEA, sendo uma característica denominada ecolalia. Quando criança, Sam também fez acompanhamento terapêutico, onde aprendeu a organizar grande parte de seus pensamentos em forma de anotações e desenhos, ficando cada vez mais fascinado pelo mundo marinho, possuindo um hiperfoco pelas espécies de pinguins que vivem na Antártida.

Quando Sam estava terminando o ensino médio tinha dúvidas sobre fazer ou não faculdade Rev. Psicol Saúde e Debate. Dez., 2020:6(2): 338-345. 
e quais seriam as opções de graduação que dariam certo com seu perfil comportamental. A professora de ética Judd (Sara Gilbert), serviu como ponte para levar Sam até uma possibilidade incrível de estudar artes, curso no qual se destacou rapidamente dos outros alunos.

Desde o primeiro dia de aula na universidade Sam chamou a atenção de seu professor Shinerock (Eric McCormack), devido sua incrível capacidade de desenhar imagens realistas de animais, na maioria das vezes marinhos e pertencentes a Antártida, porém, em cada atividade ele sentia-se ainda mais desafiado a tentar algo novo, sofrendo alterações em suas emoções e sentimentos, tendo que aprender a lidar com a falta de rotina em sua nova vida como universitário, onde sua família e amigos tiveram um papel excepcional.

\section{DISCUSSÃO}

$\mathrm{Na}$ série pode-se perceber a dificuldade de aceitação do pai que inclusive abandonou a família por algum tempo por não saber lidar com a realidade. Conforme o tempo passou Elsa e Doug perceberam o quanto seria importante participarem de reuniões com grupos de pais com filhos autistas, para compreenderem qual seria a melhor forma de ajudarem seu filho mais velho.

Estudos realizados demonstram dificuldades em relação aos pais de aceitarem ter um filho com aspectos diferenciados dos demais membros da família. Postula-se a ideia de que quando acontece uma doença ou deficiência num dos membros da família, ocorre um encadeamento de estádios emocionais e atitudinais aproximadamente constante e universal, sendo estes: choque, negação, depressão, adaptação e reorganização (Klüber-Ross, 1996).

$\mathrm{Na}$ obra analisada, o portador de TEA de alta funcionalidade enfrentou inúmeros desafios, um deles era em seu ambiente de trabalho, porém, possuía habilidades que o favoreciam, como por exemplo a pontualidade, responsabilidade em executar sua rotina e tarefas, anotando e questionando, sendo assim o mais preciso possível de acordo com suas competências e com o que Ihe era cobrado pela empresa e pelos clientes da loja de eletrônicos.

Leopoldino (2015) destaca que pessoas com TEA relatam três grandes dificuldades, no que se refere à inclusão no mercado de trabalho: dificuldade em conseguir emprego, em manter-se nele e a obtenção de uma colocação compatível com a sua formação e expectativas.

Além destes fatos, a série Atypical evidenciou que o suporte social serve como um escudo para o indivíduo com TEA de alta funcionalidade, pois quando ele sente que é tratado com respeito e compreensão isto é transmitido para ele em forma de proteção e acolhimento.

Esse fato é corroborado por Pereira (2018), ao afirmar que o suporte social é de grande importância não só para os portadores do TEA como também para toda a humanidade, porém eles necessitam de uma atenção especial devido suas peculiaridades. As famílias e os amigos possuem

Rev. Psicol Saúde e Debate. Dez., 2020:6(2): 338-345. 
um papel fundamental no desenvolvimento e aperfeiçoamento de pessoas com TEA, pois graças a eles será mostrado ao indivíduo como são estabelecidos os papeis na sociedade, por exemplo, como ele deverá tentar se comportar em determinadas situações que causem estranheza, como manter a calma ou demonstrar afeto por alguém querido (Gomes, 2015). O autista precisa se sentir acolhido pelos amigos e parentes mais próximos, fazendo com que ocorra uma diminuição na sobrecarga emocional do paciente auxiliando-o no enfrentamento (Souza et al., 2004).

Em relação ao enfrentamento, a série mostra que o terapeuta sempre indica técnicas de autocontrole em situações consideradas de risco ao paciente. Nesse contexto, Klüber-Ross (1996) aponta são necessários esforços cognitivos e comportamentais para lidar com as situações vistas como ameaças pelo portador de TEA.

O psicólogo possui um papel de imensa importância para ajudar o paciente com TEA, fazendo com que ele se sinta preparado para lidar com as adversidades do dia a dia, sentindo-se o menos frustrado possível e com capacidades de lidar com os problemas quando eles surgirem em sua direção (Souza et al., 2004).

Amiralian (1978) aborda:

[...] a atuação do psicólogo nos casos de excepcionalidade e enfatiza que, nesse campo, o psicólogo deve ter conhecimento e compreensão do desenvolvimento e aprendizagem da criança, ser conhecedor dos efeitos produzidos pela incapacidade no desenvolvimento

afetivo, perceptivo, motor e cognitivo (p. 66).

O paciente com auxílio do profissional deve aprender a organizar suas ideias de maneira produtiva, na qual consiga se expressar com o mundo externo podendo assim pedir ajuda quando necessário (Souza et al., 2004).

Nesse contexto, merece destaque a avaliação diagnóstica que no caso de uma pessoa incapacitada deve ser centralizada nas suas possibilidades, isto é, na sua capacidade de realização, independentemente de sua limitação física, intelectual ou socioemocional (Amiralian, 1978).

\section{CONSIDERAÇÕES FINAIS}

O presente trabalho tornou possível transmitir alguns conceitos a respeito do cotidiano de portadores do transtorno espectro autista de alta funcionalidade. Pretendeu-se também demonstrar de maneira clara e precisa a fundamental importância da família e do caminho que é percorrido para o entendimento das necessidades do sujeito no ambiente social.

Pode-se perceber que o autista muitas vezes não é incluso na sociedade. A partir dessa realidade, pode-se afirmar que a discussão do tema abordado é de extrema importância para que

Rev. Psicol Saúde e Debate. Dez., 2020:6(2): 338-345. 
haja maior inclusão de pacientes com TEA, pretendendo-se contribuir para o aumento de conhecimento da sociedade sobre os desafios enfrentados pelos autistas, seus familiares e amigos.

A série Atypical demonstra ao público o dia-a-dia de um jovem com TEA de alta funcionalidade, que apesar de todos os desafios que sua patologia trouxe ele foi capaz de vencer obstáculos e demonstrar que uma pessoa com TEA consegue realizar diversas tarefas e aprender inúmeras coisas no decorrer de sua vida, principalmente se tiver ao seu lado companheiros para Ihe incentivar em sua trajetória, fazendo com que ele se sinta mais seguro e motivado a executar suas ações.

\section{REFERÊNCIAS}

Amiralian, M. L. T. M. (1978). Psicologia do Excepcional. v. 8. São Paulo: EPU.

Associação Brasileira de Psiquiatria. (2013). Manual Diagnóstico e Estatístico de Transtornos Mentais. 5. ed. Arlington: Autor.

Delion, P. (2015). Autismo e parentalidade; Estilos clin., 20(1), 15-26.

Klüber-Ross, E. (1996). Sobre a morte e o morrer. São Paulo: Martins Fontes.

Leopoldino, C. B. (2015). Inclusão de autistas no mercado de trabalho: uma nova questão de pesquisa. Revista Eletrônica Gestão \& Sociedade. 9 (22), 853-868.

Maia, F. A., Almeida, M. T. C., Alves, M. R., Bandeira, L. V. S. Silva, V. B., Nunes, N. F et al. (2018). Transtorno do espectro do autismo e idade dos genitores: estudo de caso-controle no Brasil. Caderno Saúde Pública, 34(8), e00109917.

Marques, M. H., \& Dixe, M. A. R. (2011). Crianças e jovens autistas: impacto na dinâmica familiar e pessoal de seus pais. Archives of Clinical Psychiatry, 38(2), 66-70.

Souza, J. C., Fraga, L. L., Oliveira, M. R., Buchara, M. S., Straliotto N. C., Rosário, S. P. et al. (2004). Atuação do psicólogo frente aos transtornos globais do desenvolvimento infantil. Psicologia Ciência e Profissão, 24(2), 24-31.

Pereira, A. I. L., Fernandes, O. M., Relva, I. C., (2018). Sintomatologia psicopatológica e suporte social em pais de crianças portadoras de perturbação do espetro do autismo Aná. Psicológica, 36(3), 327-340.

Gomes, P. T. M., Lima, L. H. L., Bueno, M. K. G., Liubiana, A. Araújo, L. A., Souza, N. M., (2015). Autismo no Brasil, desafios familiares e estratégias de superação: revisão sistemática. J. Pediatr. (Rio J.) 91(2), 111-121.

Souza, J. C., Fraga, L. L., Oliveira, M. R., Buchara, M. S., Straliotto, N. C., Rosário, S. P., Rezende, T. M. (2004) Atuação do Psicólogo Frente aos Transtornos Globais do Desenvolvimento Infantil. Psicologia ciência e profissão, 24 (2), 24-31. 